\title{
Article \\ Apolipoprotein E4 Is Associated with Right Ventricular Dysfunction in Dilated Cardiomyopathy-An Animal and In-Human Comparative Study
}

\author{
Rodica Diaconu ${ }^{1,2} \oplus$, Nicole Schaaps ${ }^{3}$, Mamdouh Afify ${ }^{3,4}$, Peter Boor ${ }^{5} \oplus$, Anne Cornelissen ${ }^{3}$, \\ Roberta A. Florescu ${ }^{3}$, Sakine Simsekyilmaz ${ }^{6}$, Teddy El-Khoury ${ }^{3}$, David Schumacher ${ }^{7,8}{ }^{\mathbb{D}}$, Mihai Ioana $^{1}$, \\ Ioana Streata ${ }^{1}$, Constantin Militaru ${ }^{2}$, Ionut Donoiu ${ }^{2}$ (D), Felix Vogt ${ }^{3}$ and Elisa A. Liehn $1,3,9,10, *$ (D)
}

check for updates

Citation: Diaconu, R.; Schaaps, N.; Afify, M.; Boor, P.; Cornelissen, A.; Florescu, R.A.; Simsekyilmaz, S.; El-Khoury, T.; Schumacher, D.; Ioana, M.; et al. Apolipoprotein E4 Is Associated with Right Ventricular Dysfunction in Dilated Cardiomyopathy-An Animal and In-Human Comparative Study. Int. J. Mol. Sci. 2021, 22, 9688. https:// doi.org/10.3390/ijms22189688

Academic Editors: Francesco Fedele and Paul J. Mather

Received: 19 August 2021

Accepted: 30 August 2021

Published: 7 September 2021

Publisher's Note: MDPI stays neutral with regard to jurisdictional claims in published maps and institutional affiliations.

Copyright: (c) 2021 by the authors. Licensee MDPI, Basel, Switzerland. This article is an open access article distributed under the terms and conditions of the Creative Commons Attribution (CC BY) license (https:// creativecommons.org/licenses/by/ $4.0 /$ )
1 Human Genetic Laboratory, Faculty of Medicine, University of Medicine and Pharmacy, 200349 Craiova, Romania; rodica.diaconu91@gmail.com (R.D.); mihai.ioana@umfcv.ro (M.I.); ioana.streata@yahoo.com (I.S.)

2 Department of Cardiology, University of Medicine and Pharmacy, 200349 Craiova, Romania; cccmilitaru@yahoo.com (C.M.); i.donoiu@gmail.com (I.D.)

3 Department of Cardiology, Angiology and Intensive Care, Medical Faculty, RWTH Aachen University, 52074 Aachen, Germany; nschaaps@ukaachen.de (N.S.); mafify@ukaachen.de (M.A.); acornelissen@ukachen.de (A.C.); rflorescu@ukaachen.de (R.A.F.); telkhoury@ukaachen.de (T.E.-K.); fvogt@ukaachen.de (F.V.)

4 Department of Pathology, Faculty of Veterinary Medicine, Cairo University, Giza 12211, Egypt

5 Medical Faculty, Institute of Pathology, RWTH Aachen University, 52074 Aachen, Germany; pboor@ukaachen.de

6 Department for Pharmacology and Clinical Pharmacology, Medical Faculty, University Hospital Düsseldorf, 40225 Düsseldorf, Germany; sakine@gmx.de

7 Department of Anesthesiology, Medical Faculty, RWTH Aachen University, 52074 Aachen, Germany; dschumacher@ukaachen.de

8 Medical Faculty, Institute of Experimental Medicine and Systems Biology, RWTH Aachen University, 52074 Aachen, Germany

9 Medical Faculty, Institute for Molecular Cardiovascular Research (IMCAR), RWTH Aachen University, 52074 Aachen, Germany

10 Institute for Pathology "Victor Babes", 050096 Bucharest, Romania

* Correspondence: eliehn@ukaachen.de

Abstract: ApoE abnormality represents a well-known risk factor for cardiovascular diseases. Beyond its role in lipid metabolism, novel studies demonstrate a complex involvement of apoE in membrane homeostasis and signaling as well as in nuclear transcription. Due to the large spread of apoE isoforms in the human population, there is a need to understand the apoE's role in pathological processes. Our study aims to dissect the involvement of apoE in heart failure. We showed that apoEdeficient rats present multiple organ damages (kidney, liver, lung and spleen) besides the known predisposition for obesity and affected lipid metabolism (two-fold increase in tissular damages in liver and one-fold increase in kidney, lung and spleen). Heart tissue also showed significant morphological changes in apoE $\mathrm{E}^{-/-}$rats, mostly after a high-fat diet. Interestingly, the right ventricle of $\mathrm{apoE}^{-/-}$rats fed a high-fat diet showed more damage and affected collagen content $(\sim 60 \%$ less total collagen content and double increase in collagen1/collagen3 ratio) compared with the left ventricle (no significant differences in total collagen content or collagen1/collagen3 ratio). In patients, we were able to find a correlation between the presence of $\varepsilon 4$ allele and cardiomyopathy $\left(\chi^{2}=10.244 ; p=0.001\right)$, but also with right ventricle dysfunction with decreased TAPSE $(15.3 \pm 2.63 \mathrm{~mm}$ in $\varepsilon 4$-allele-presenting patients vs. $19.8 \pm 3.58 \mathrm{~mm}$ if the $\varepsilon 4$ allele is absent, $p<0.0001^{*}$ ) and increased in systolic pulmonary artery pressure $(50.44 \pm 16.47 \mathrm{mmHg}$ in $\varepsilon 4$-allele-presenting patients vs. $40.68 \pm 15.94 \mathrm{mmHg}$ if the $\varepsilon 4$ allele is absent, $p=0.0019$ ). Our results confirm that the presence of the $\varepsilon 4$ allele is a lipid-metabolism-independent risk factor for heart failure. Moreover, we show for the first time that the presence of the $\varepsilon 4$ allele is associated with right ventricle dysfunction, implying different regulatory mechanisms of fibroblasts and the extracellular matrix in both ventricles. This is essential to be considered and thoroughly investigated before the design of therapeutical strategies for patients with heart failure. 
Keywords: apoE; cardiovascular models; dilated cardiomyopathy; right ventricular systolic dysfunction; $\varepsilon 4$ allele

\section{Introduction}

Apolipoprotein (apo) E abnormality and disturbed lipid transportation represent wellknown risk factors for cardiovascular diseases [1-3]. However, new studies demonstrate a complex involvement of apoE in membrane homeostasis and signaling as well as in nuclear transcription [4]. Due to the large spread of apoE isoforms in the human population, there is a need to understand apoE's role in pathological processes to explain the current therapeutic failure in some patients and to develop proper personalized therapeutic strategies.

There are six different apoE genotypes: three homozygotes $(\varepsilon 2 \varepsilon 2, \varepsilon 3 \varepsilon 3, \varepsilon 4 \varepsilon 4)$ and three heterozygotes $(\varepsilon 2 \varepsilon 3, \varepsilon 3 \varepsilon 4, \varepsilon 2 \varepsilon 4)$. The $\varepsilon 3 \varepsilon 3$ genotype is considered wild-type [5], as it is the most common with a prevalence of $62 \%$ in the population [4]. $\varepsilon 4$ allele carriers seem to have the highest risk for coronary heart disease and stroke, being equivalent to a dysfunctional apoE gene and imitating the genetical deletion in animal models. Besides the risk for developing atherosclerosis, $\varepsilon 4$ allele carriers also seem to develop dilated cardiomyopathy [6]. Dilated cardiomyopathy is a progressive disease consisting of heart wall thinning and a gradual increase in left ventricular end-diastolic and end-systolic volumes, evolving towards heart failure with reduced ejection fraction and representing the third cause of heart failure in regard to frequency and the most common disease for which cardiac transplantation is required [7].

Since the involvement of apoE in the pathology of dilated cardiomyopathy is still not known, the aim of the study is to investigate the lipid-independent effects of apoE on heart tissue and the possible correlation with non-ischemic heart pathology in animals and humans.

\section{Results}

Time- and diet-dependent changes in blood composition in apoE knockout $\left(\mathrm{apoE}^{-/-}\right)$ rats were analyzed.

Wild-type and apoE ${ }^{-/-}$rats were fed a normal or high-fat diet over 12 weeks. Blood analyses were performed at the indicated time points. As expected, a high-fat diet induced a significant increase in the weight of the rats; however, this was seen in both wild-type and apoE $\mathrm{E}^{-/-}$rats (Figure 1A). Further, the high-fat diet induced a significant increase in blood lipids, such as cholesterin (Figure 1B), low-density lipoprotein (LDL, Figure 1D) and high-density lipoprotein (HDL, Figure 1E) only in apoE ${ }^{-/-}$rats, while in apoE ${ }^{-/}$fed a normal diet and wild-type rats, these lipids remained unchanged. Another pattern was seen in triglyceride concentrations (Figure 1C). In wild-type rats, the high-fat diet induced a significant triglyceride concentration increase over time, whereas in apo $\mathrm{E}^{-/-}$rats, the triglyceride concentration was increased at a constant level. Further, the high-fat diet induced increase in acid uric (Figure $1 \mathrm{H}$ ) in both groups over time; however, only apoE $\mathrm{E}^{-/-}$rats showed a deterioration of renal function, as determined by increased creatinine concentration (Figure 1F). Albumin (Figure 1G), glucose (Figure 1I) and blood cells, such as total leukocytes (Figure 1J), lymphocytes (Figure 1K), monocytes (Figure 1L), granulocytes (Figure 1M), erythrocytes (Figure 1N) and platelets (Figure 1P), were not affected by genotype or the high-fat diet.

\subsection{Morphological Changes Induced by High-Fat Diet in Different Organs}

Stained sections from different organs were analyzed regarding the cellular and morphological changes induced by the high-fat diet. Almost all organs presented pathological changes in old apoE ${ }^{-/-}$rats, independently of diet. 

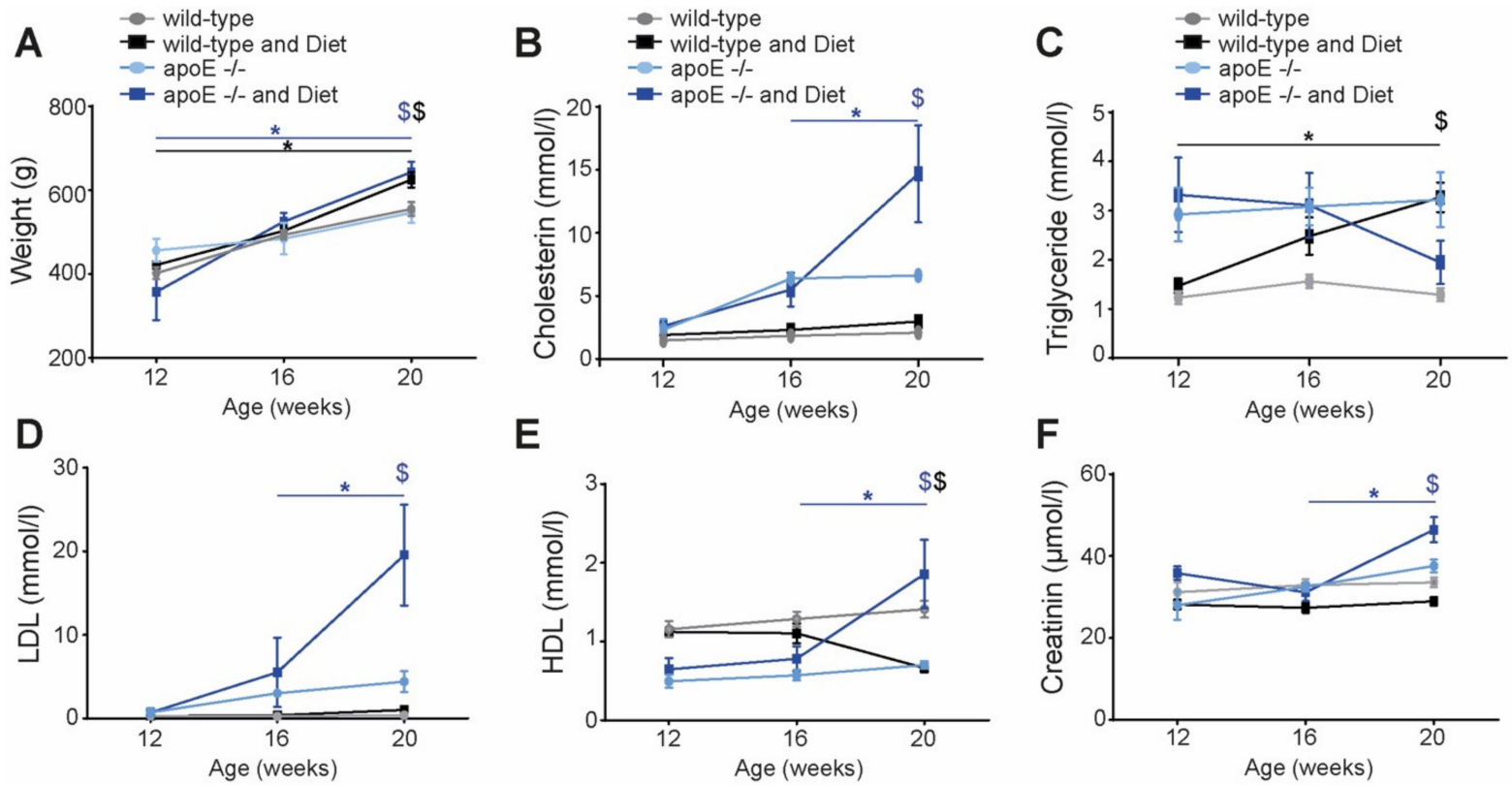

$\mathbf{E}$
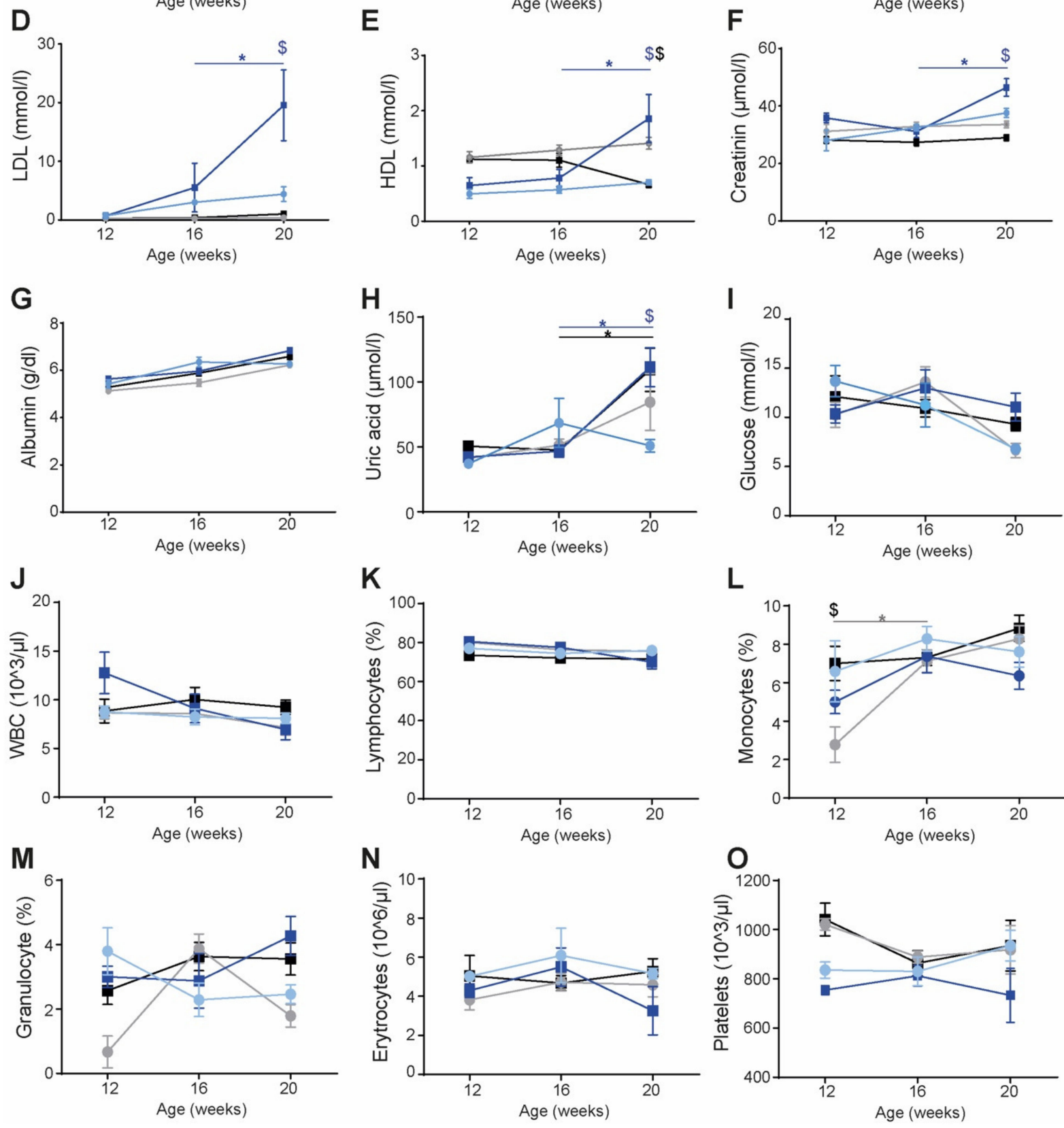

Figure 1. Blood analysis of $\mathrm{apoE}^{-/-}$rats at different time points under feeding high-fat diet (A-O). Indicated parameters and cell components were determined after 4 weeks (age 12 weeks), 8 weeks (age 16 weeks) and 12 weeks (age 20 weeks), respectively $(n=5-15)$, under normal diet (bright blue for apoE ${ }^{-/}$and grey for wild-type rats) or high-fat diet (dark blue for apoE ${ }^{-/-}$and black for wild-type rats). ${ }^{*} p<0.05$ vs. earlier time points, ${ }^{\$} p<0.05$ high-fat vs. normal diet (in black for wild-type and in blue for apoE $\mathrm{E}^{-/-}$rats). 
The liver was most susceptible and presented signs of hepatocellular vacuolization, fat deposition and focal necrosis after the high-fat diet in both wild-type and apoE ${ }^{-/-}$ rats (Figure 2A) after feeding of the high-fat diet. However, the pathological changes were significantly increased in apo $\mathrm{E}^{-/-}$rats compared with the wild-type rats.

A
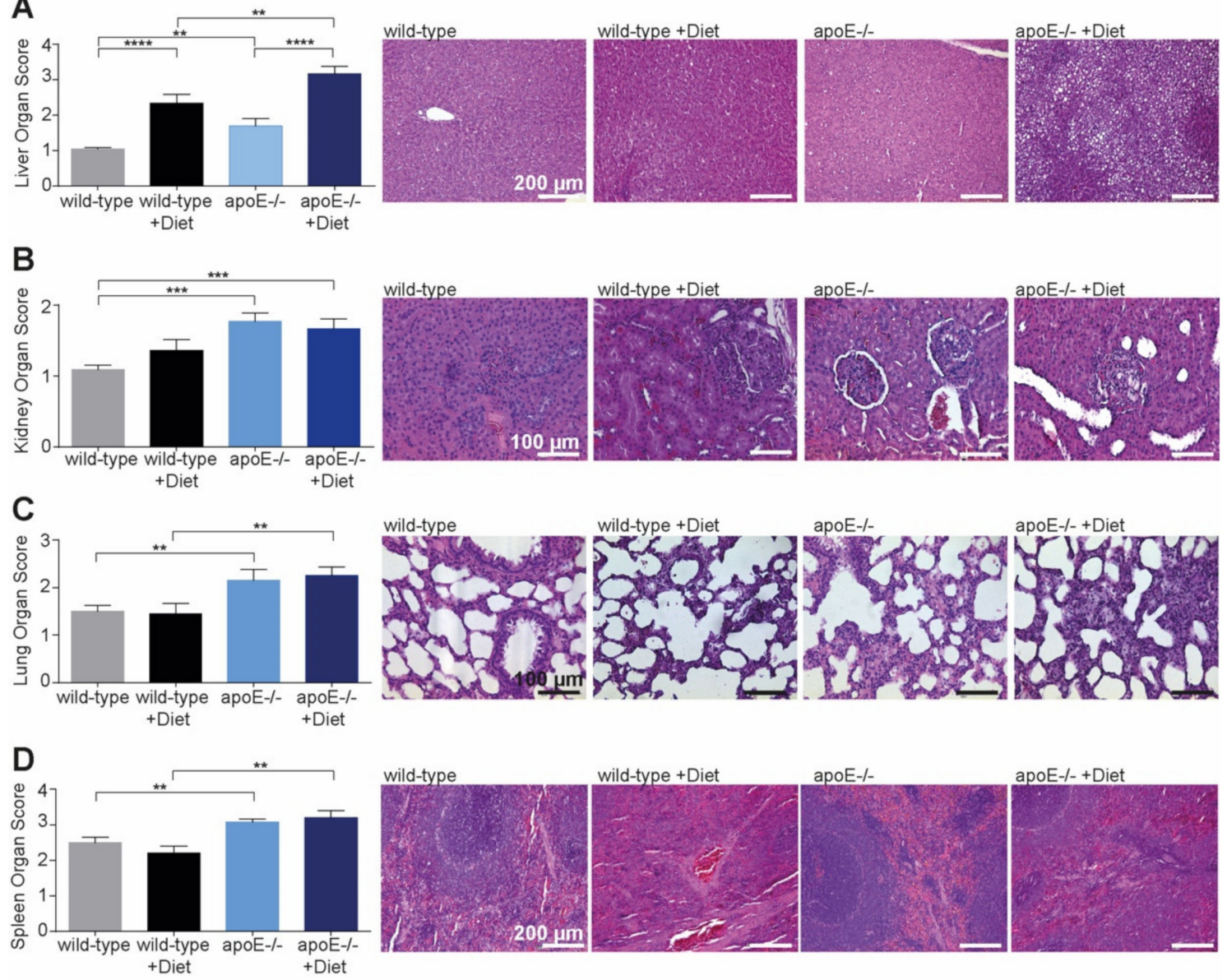

apoE- $/$ - +Diet
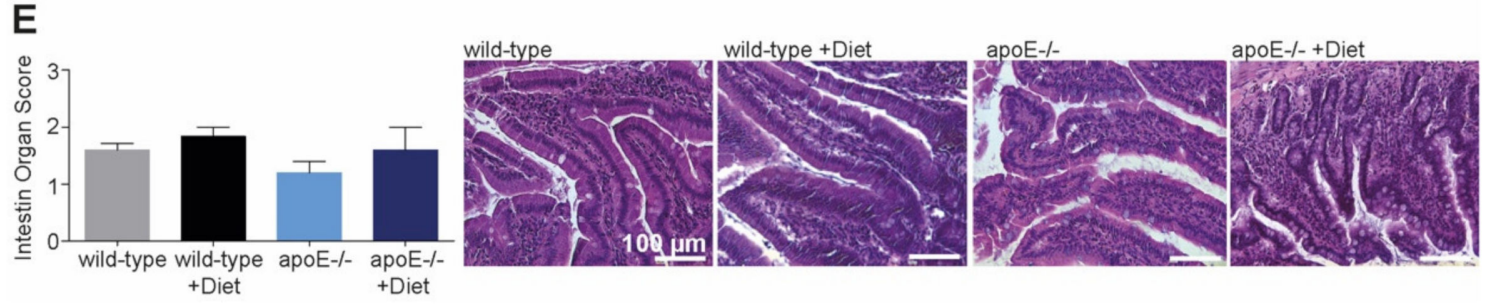

Figure 2. Changes in organ morphology of $\mathrm{apoE}^{-/-}$rats after feeding high-fat diet (A-E). Twelve weeks (age 20 weeks) after feeding normal or high-fat diet, $\mathrm{apoE}^{-/-}$rats showed pathological changes in almost all organs compared with wild-type rats. While pathological changes in kidney, lung, and spleen were not related to diet, the liver was dramatically affected by high-fat diet, especially in apoE ${ }^{-/-}$. ${ }^{* *} p<0.0,{ }^{* * *} p<0.001,{ }^{* * *} p<0.0001, n=5-15$, scale bar is indicated in the first image of each group.

Independently of diet type, the kidneys of $\mathrm{apoE}^{-/-}$rats presented increased signs of vacuolization, congestion and glomerular membrane thickening compared with wild-type rats (Figure 2B). Similarly, we found more edema, congestion and thickness of the alveolar wall in the lung (Figure 2C) of apoE $\mathrm{E}^{-/-}$rats, while the spleen (Figure 2D) showed more lymphoid hyperplasia and congestion in $\mathrm{apoE}^{-/-}$rats compared with wild-type rates.

No changes were observed in intestine morphology (Figure 2E) in wild-type and $\mathrm{apoE}^{-/-}$rats fed or not fed a high-fat diet. 


\subsection{Heart Morphological Changes in $A p o E^{-1-}$ Fed or Not High-Fat Diet}

Heart tissue was analyzed separately in the left (Figure 3A) and right ventricle (Figure 3B). Both ventricles presented loose interstitial tissue (Figure $3 \mathrm{C}$ ) in $\mathrm{apoE}^{-/-}$rats fed the highfat diet, suggesting defects in the extracellular matrix in preserving the structural integrity. Similarly, we detected increased areas of necrosis (Figure 3D) in both ventricles in apoE $\mathrm{E}^{-/-}$ rats after feeding the high-fat diet, suggesting more susceptible myocardium in this group. No differences in the vacuolization of the cells were observed (Figure 3E). Further, the right myocardium of apoE ${ }^{-/-}$rats fed the high-fat diet showed increased bundles of thin tissue (Figure 3F) and mononuclear cell infiltration (Figure 3G), while the left myocardium showed more prominent edema (Figure $3 \mathrm{H}$ ).

A
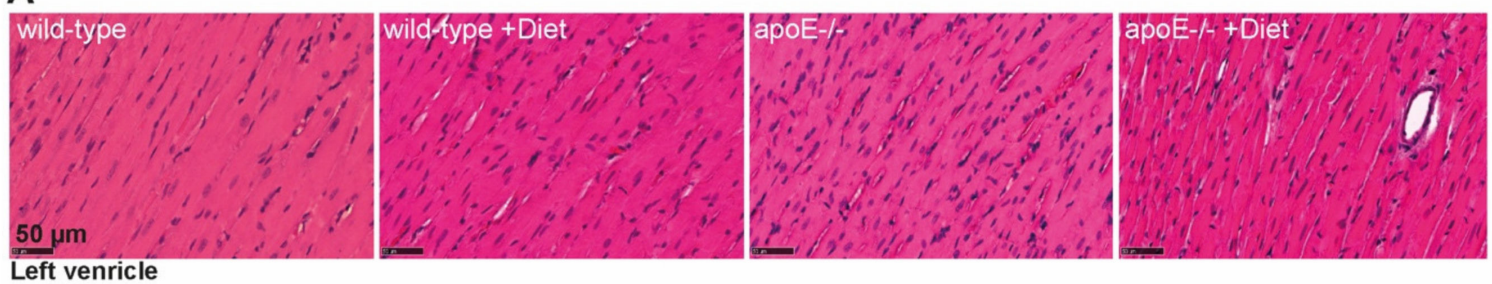

B
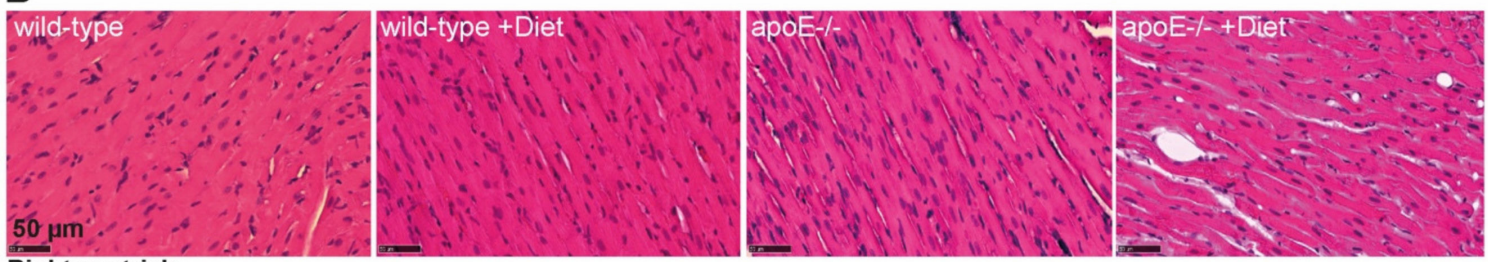

Right ventricle

C

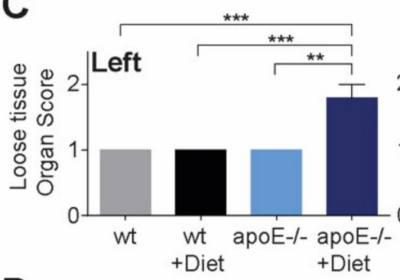

D

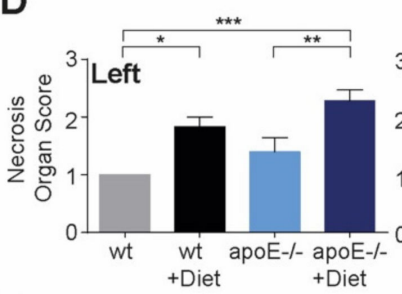

E
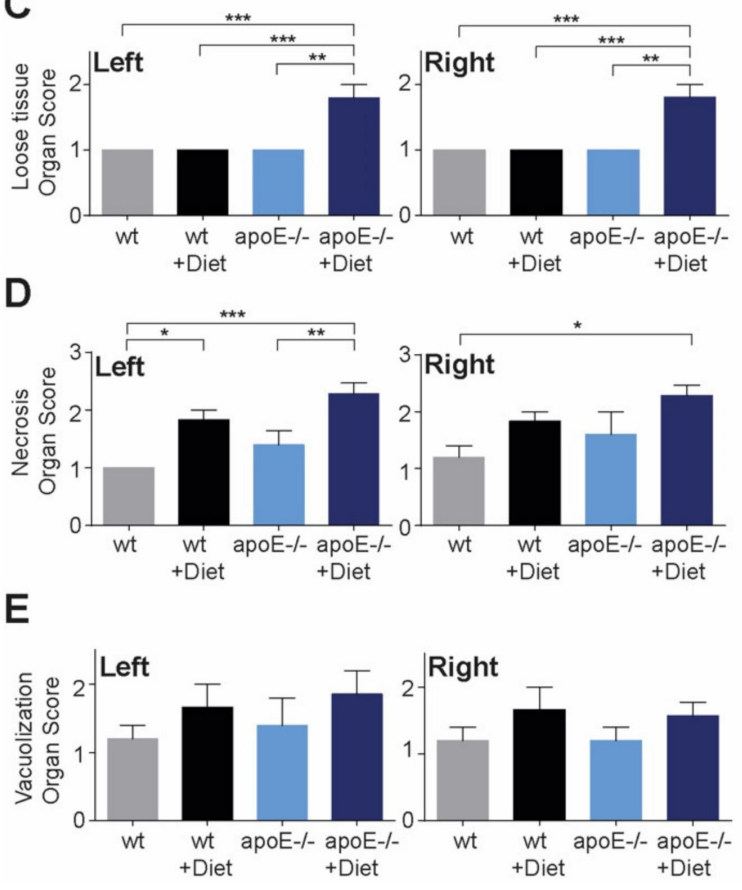

F

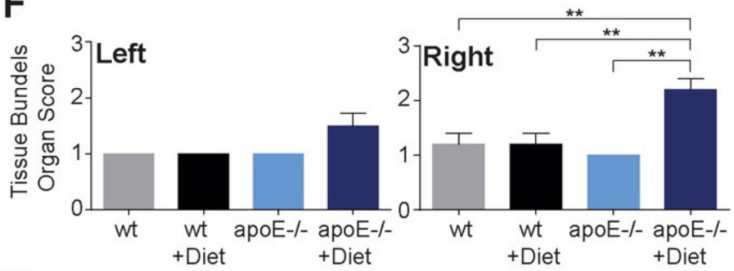

G

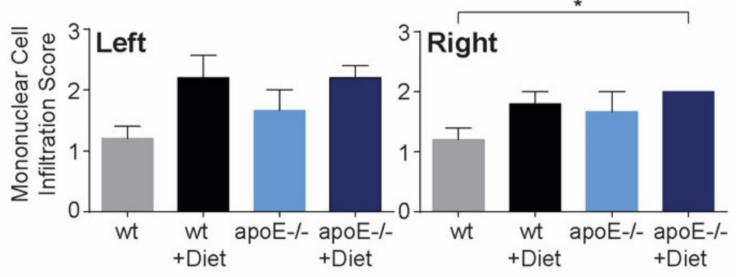

H

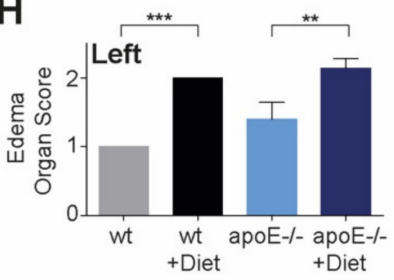

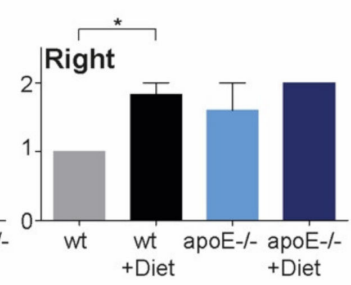

Figure 3. Changes in heart morphology of $a p o E^{-/-}$rats after feeding high-fat diet Twelve weeks (age 20 weeks) after feeding normal or high-fat diet, apoE ${ }^{-/}$rats showed differentiated pathological changes in left and right ventricle compared with wild-type rats $(\mathbf{A}-\mathbf{H})$. While interstitial tissue of each ventricle was equally affected and presented necrosis foci, the right ventricle showed more thin tissue bundles and mononuclear cell infiltration and the left ventricle, more edema in $\mathrm{apoE}^{-/-}$rats fed with high-fat diet. ${ }^{*} p<0.5,{ }^{* *} p<0.01,{ }^{* * *} p<0.001, n=5-15$, scale bar is indicated in the first image of each group. 


\subsection{Histomorphometrical Characterization of Hearts in $A p o E^{-/-}$Rats Fed with Normal or High-Fat Diet}

Since many studies point out the role of apoE $\mathrm{P}^{-/-}$in the development of dilatative cardiomyopathy, we performed histological measurements of heart cavities and walls. While wall thickness presented a slight tendency to decrease (Figure 4A) and ventricular cavity to increase (Figure $4 \mathrm{~B}$ ) in apoE ${ }^{-/-}$rats fed the high-fat diet, the measurements were not significant either in the left or right ventricle.

A
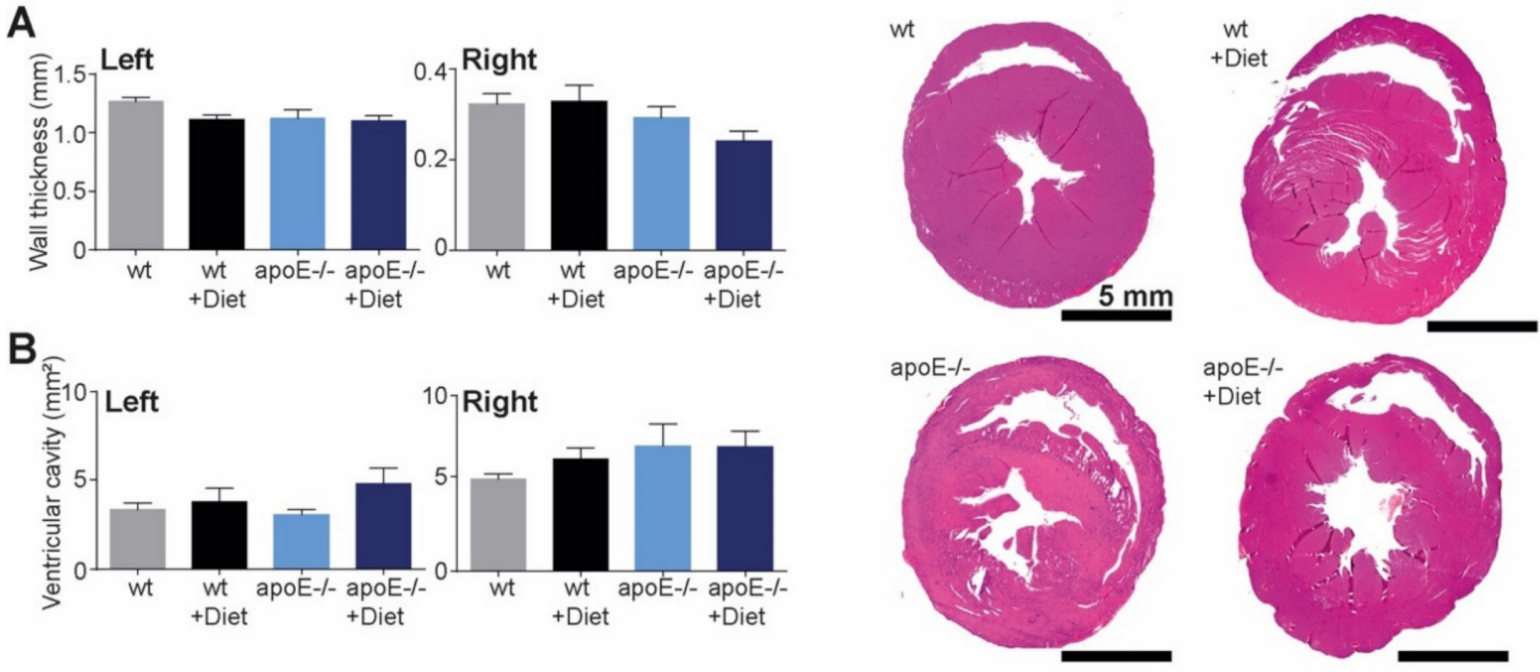

C
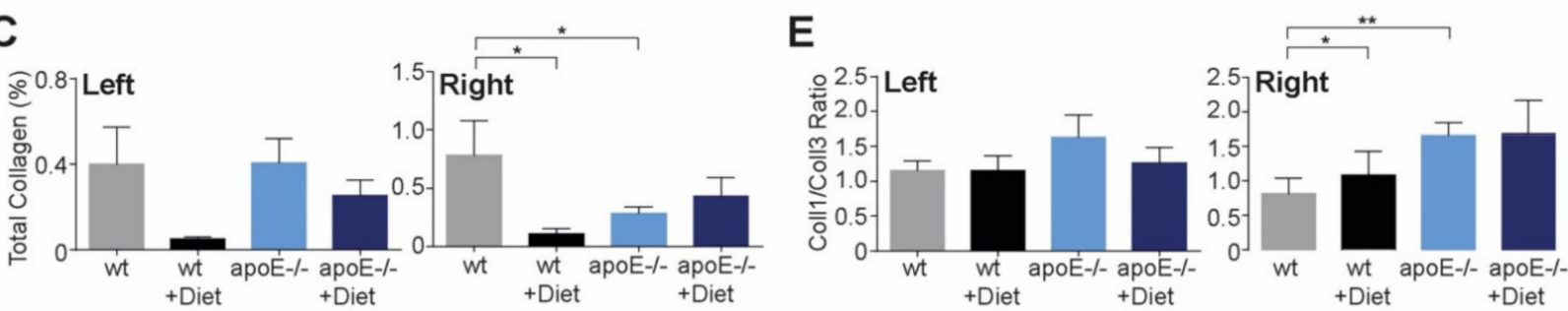

D
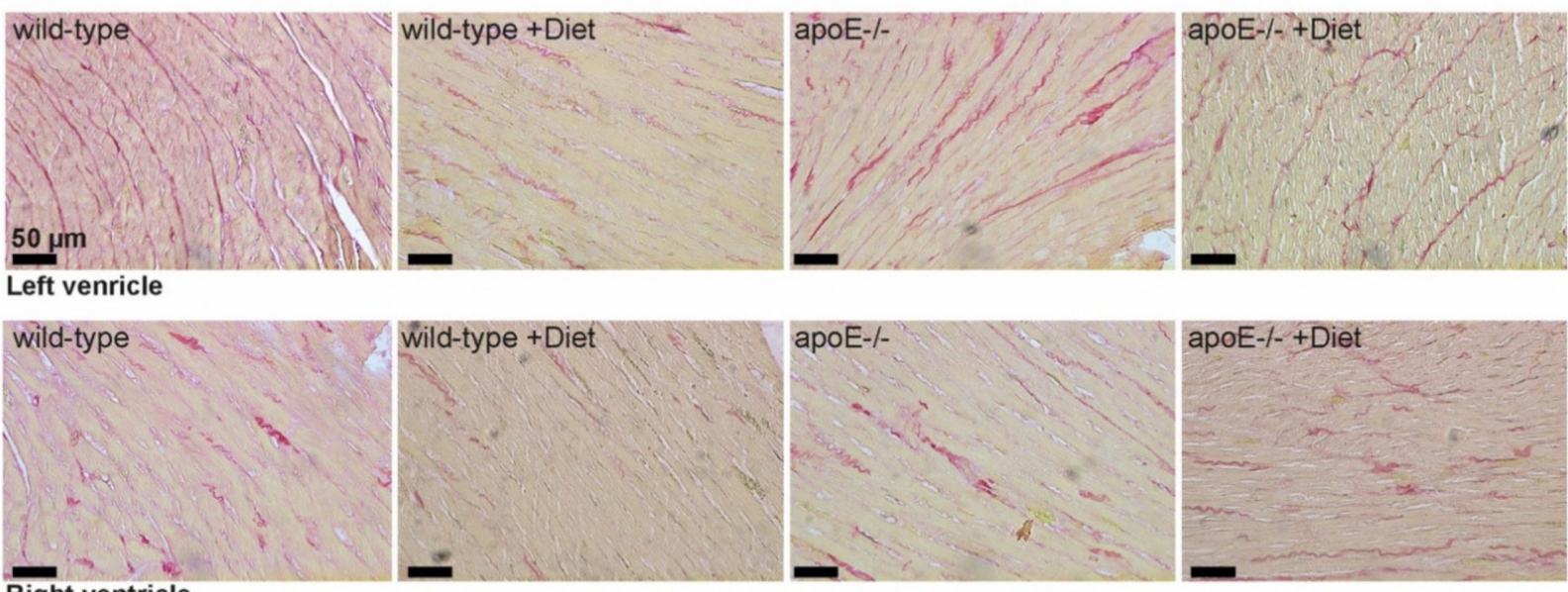

Figure 4. Histomorphometrical characterization of hearts in apoE $\mathrm{E}^{-/-}$rats fed normal or high-fat diet (A-D). Twelve weeks (age 20 weeks) after feeding normal or high-fat diet, apoE ${ }^{-/-}$rats showed no differences in the heart dimensions compared with wild-type rats, while the right ventricle showed a decrease in collagen deposition and increased collagen1/collagen3 ratio in apoE ${ }^{-/-}$rats or rats fed high-fat diet. ${ }^{*} p<0.5,{ }^{* *} p<0.01, n=5-15$, scale bar is indicated in the first image of each group. 
Collagen content was only significantly decreased in the right ventricle of rats fed the high-fat diet, and with an apoE ${ }^{-/-}$background (Figure $4 \mathrm{C}, \mathrm{D}$ ), while no significant changes were observed in the left ventricle. Similarly, the collagen1/collagen3 ratio was only increased in the right ventricle of apoE ${ }^{-/-}$rats, while in the left ventricle it remained unchanged (Figure 4E).

\subsection{Study Group Population and Characteristics}

For the validation of the results from the animal study, we further investigated the correlation between the human apoE allele with dimensional and functional heart parameters.

For this purpose, a total of 111 consecutive Caucasian patients ( 85 males) with advanced heart failure (mean age $66 \pm 8.68$ years) were included: 50 with ischemic cardiomyopathy (ICM) and 61 with dilated cardiomyopathy (DCM) (Figure 5A). The diagnosis was based on echocardiography and coronary angiogram. The mean left ventricular ejection fraction was $28.3 \pm 6 \%$, and the mean NYHA class was $2.93 \pm 1.2$. A total of 187 (131 males) controls (mean age $57 \pm 10.3$ years) were selected from healthy volunteers (Figure 5B). The main characteristics of the cohorts are presented in Table 1.

A

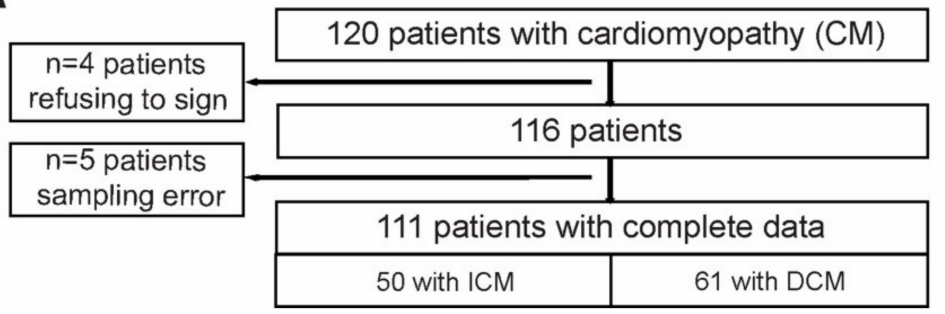

B

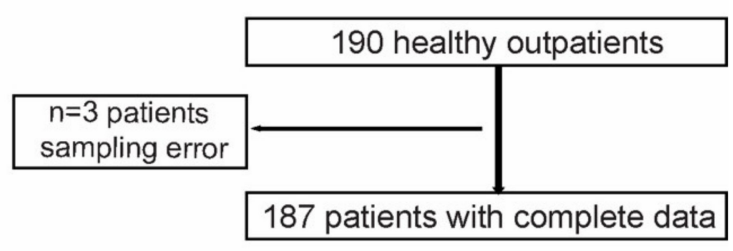

Figure 5. Study design. Patients with cardiomyopathy (A) and the healthy volunteers (B) recruited for the current study.

Table 1. Demographics and clinical characteristics of control and patient groups.

\begin{tabular}{cccc}
\hline Variable & $\begin{array}{c}\text { CM Patients } \\
\boldsymbol{n}=\mathbf{1 1 1}\end{array}$ & $\begin{array}{c}\text { Controls } \\
\boldsymbol{n}=\mathbf{1 8 7}\end{array}$ & $\boldsymbol{p}$ Value \\
\hline Age (years) & $66 \pm 8.68$ & $57 \pm 10.3$ & $p<0.01$ \\
Sex (male) & $86(77.48 \%)$ & $131(70.06 \%)$ & $\mathrm{N}$ \\
BMI, kg/m ${ }^{2}$ & $27.78 \pm 4.90$ & $26.56 \pm 3.89$ & $\mathrm{~N}$ \\
Alcohol, $n(\%)$ & $13(11.71 \%)$ & $33(17.65 \%)$ & $\mathrm{N}$ \\
Smoking, $n(\%)$ & $29(26.13 \%)$ & $95(50.8 \%)$ & $p<0.01$ \\
\hline
\end{tabular}

\subsection{Comparison of Genotype Frequency and Allele Frequency between Groups}

There was a significant difference in apoE genotype between $\mathrm{CM}$ patients and the control groups (Table 2 and Figure $6 \mathrm{~A}$ ). We found the $\varepsilon 4$ allele frequency to be significantly higher in the CM patients group compared to the control $\left(\chi^{2}=10.244 ; p=0.001\right)$. CM patients presented a significant increase in the $\varepsilon 3 / \varepsilon 4$ genotype frequency compared to the controls $\left(\chi^{2}=11.012 ; \mathrm{OR}=2.31,95 \% \mathrm{Cl}=1.404-3.831 ; p<0.001\right)$. Further, the frequency of allele $\varepsilon 2$ was higher in the CM patients $\left(\chi^{2}=4.349 ; p=0.03\right)$, whereas as expected, the frequency of the $\varepsilon 3 / \varepsilon 3$ genotype was found to be significantly higher in the controls compared to patients $\left(\chi^{2}=16.069 ; p=0.0001\right)$.

Comparing the frequency of different genotypes inside the CM patients group, there were no significant differences between the patients with ICM or DCM (Table 3). The presence of the $\varepsilon 2 / \varepsilon 3$ genotype was more frequent in the group of patients with ICM $(p=0.019)$ (Table 3, Figure 6B). However, due to the small number of patients presented these alleles (eight patients for ICM and two patients for DCM) this result would need confirmation with higher patient numbers. 
Table 2. The apoE genotype in CM patients and control group.

\begin{tabular}{cccccc}
\hline & $\begin{array}{c}\text { CM Patients } \\
(\boldsymbol{n}=\mathbf{1 1 1})\end{array}$ & $\begin{array}{c}\text { Control } \\
(\boldsymbol{n}=\mathbf{1 8 6})\end{array}$ & $\boldsymbol{p}$-Value & $\begin{array}{c}\text { Odds } \\
\text { Ratio }\end{array}$ & $\begin{array}{c}\text { 95\% Confidence } \\
\text { Interval }\end{array}$ \\
\hline Allelle & Allellic count $(\%)$ & Allellic count $(\%)$ & & 0.58 & $0.183-1.855$ \\
$\varepsilon 3$ & $105(94.59 \%)$ & $180(96.25 \%)$ & 0.35 & 2.21 & $1.355-3.611$ \\
$\varepsilon 4$ & $52(46.85 \%)$ & $53(28.49 \%)$ & 0.001 & 0.24 & $1.034-4.857$ \\
$\varepsilon 2$ & $16(14.41 \%)$ & $13(6.9 \%)$ & & 0.38 & $0.231-0.610$ \\
Genotype & $n(\%)$ & $n(\%)$ & 0.0001 & 2.31 & $1.404-3.831$ \\
$\varepsilon 3 / \varepsilon 3$ & $47(42.34 \%)$ & $123(66.12 \%)$ & 0.0009 & 0.51 & $0.202-1.306$ \\
$\varepsilon 3 / \varepsilon 4$ & $48(43.24 \%)$ & $46(24.73 \%)$ & 0.15 & 0.29 & $0.026-3.287$ \\
$\varepsilon 2 / \varepsilon 3$ & $10(9 \%)$ & $9(4.8 \%)$ & 0.29 & 2.28 & $0.501-10.383$ \\
$\varepsilon 2 / \varepsilon 2$ & $2(1.8 \%)$ & $1(0.5 \%)$ & 0.27 & & \\
$\varepsilon 2 / \varepsilon 4$ & $4(3.6 \%)$ & $3(1.6 \%)$ & 0.11 & & \\
$\varepsilon 4 / \varepsilon 4$ & & $4(2.1 \%)$ & & & \\
\hline
\end{tabular}

A

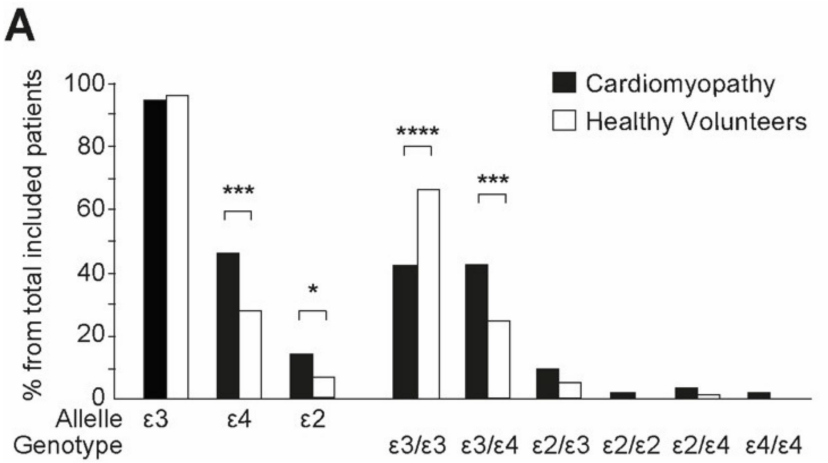

B

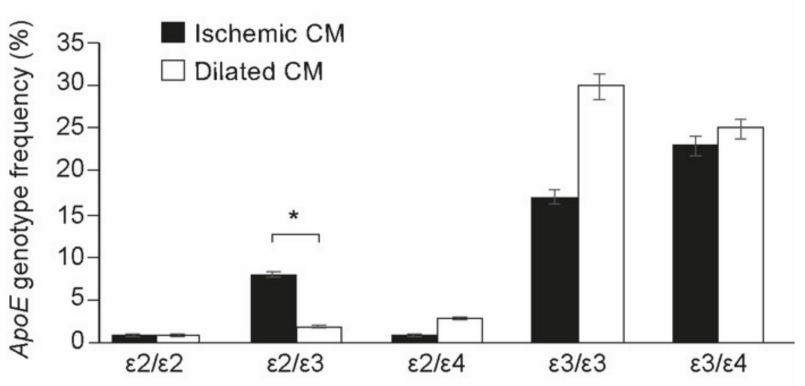

Figure 6. Genotype frequency and allele frequency between the groups. (A) Patients with cardiomyopathy (black columns) present $\varepsilon 2$ and $\varepsilon 4$ alleles more frequently as compared with controls (white columns). (B) The distribution of different alleles was not dependent on ischemic (black columns) or non-ischemic (white columns) etiology of cardiomyopathy $\left({ }^{*} p<0.5,{ }^{* * *} p<0.001 ;{ }^{* * * *} p<0.0001\right)$.

Table 3. The apoE genotype based on CM etiology.

\begin{tabular}{ccccc}
\hline & ICM $(\boldsymbol{n}=\mathbf{5 0 )}$ & DCM $(\boldsymbol{n}=\mathbf{6 1 )}$ & $\boldsymbol{X}^{\mathbf{2}}$ & $p$-Value \\
\hline Allelle & Allellic count $(\%)$ & Allellic count $(\%)$ & & \\
$\varepsilon 3$ & $48(96 \%)$ & $57(93.44 \%)$ & 0.315 & 0.554 \\
$\varepsilon 4$ & $24(48 \%)$ & $28(45.9 \%)$ & 0.485 & 0.825 \\
$\varepsilon 2$ & $10(20 \%)$ & $6(9.8 \%)$ & 2.537 & 0.111 \\
Genotype & $n(\%)$ & $n(\%)$ & & \\
$\varepsilon 3 / \varepsilon 3$ & $17(34 \%)$ & $30(49.18 \%)$ & 2.593 & 0.108 \\
$\varepsilon 3 / \varepsilon 4$ & $23(46 \%)$ & $25(40.98 \%)$ & 0.499 & 0.481 \\
$\varepsilon 2 / \varepsilon 3$ & $8(16 \%)$ & $2(3.28 \%)$ & 5.425 & 0.019 \\
$\varepsilon 2 / \varepsilon 2$ & $1(2 \%)$ & $1(1.64 \%)$ & 0.021 & 0.886 \\
$\varepsilon 2 / \varepsilon 4$ & $1(2 \%)$ & $3(4.91 \%)$ & 0.674 & 0.412 \\
\hline
\end{tabular}

\subsection{The Main Characteristics of the Patient According to $\varepsilon 4$ Allele Presence}

Since the $\varepsilon 4$ allele seems to correlate with increased cardiovascular events [4], we analyzed the influence of the $\varepsilon 4$ allele on heart function. LVEF was significantly reduced in the presence of the $\varepsilon 4$ allele compared to the patients without the $\varepsilon 4$ allele. Moreover, the presence of the $\varepsilon 4$ allele was associated with significantly increased pulmonary hypertension and dysfunctional right ventricle compared to the patients without the $\varepsilon 4$ allele (Table 4). 
Table 4. The main characteristics of the patient according to $\varepsilon 4$ presence.

\begin{tabular}{|c|c|c|c|}
\hline & $\begin{array}{l}\varepsilon 4 \text { Present } \\
(n=52)\end{array}$ & $\begin{array}{c}\varepsilon 4 \text { Absent } \\
(n=59)\end{array}$ & $p$-Value \\
\hline Age, years (Range) & $67.8(40-93)$ & $64.35(28-88)$ & 0.1250 \\
\hline Male gender, $n(\%)$ & $42(80.8 \%)$ & $44(74.6 \%)$ & 0.0910 \\
\hline BMI, $\mathrm{kg} / \mathrm{m}^{2}$ & $26.56 \pm 3.89$ & $28.46 \pm 5.60$ & 0.5684 \\
\hline \multicolumn{4}{|c|}{ Risk Factors } \\
\hline Alcohol, $n(\%)$ & $3(5.7 \%)$ & $10(16.9 \%)$ & $\mathrm{N}$ \\
\hline Smoking, $n(\%)$ & $11(21.1 \%)$ & $18(30.5 \%)$ & $\mathrm{N}$ \\
\hline Diabetes, $n(\%)$ & $23(44.2 \%)$ & $20(33.9 \%)$ & $\mathrm{N}$ \\
\hline \multicolumn{4}{|c|}{ NYHA classification } \\
\hline 1 & $3(5.8 \%)$ & $6(10.2 \%)$ & $\mathrm{N}$ \\
\hline 2 & $2(3.8 \%)$ & $7(11.9 \%)$ & $\mathrm{N}$ \\
\hline 3 & $30(57.7 \%)$ & $30(50.8 \%)$ & $\mathrm{N}$ \\
\hline 4 & $17(32.7 \%)$ & $16(27.1 \%)$ & $\mathrm{N}$ \\
\hline \multicolumn{4}{|c|}{ DCM etiology } \\
\hline Non-ischemic & $23(44.2 \%)$ & $28(47.5 \%)$ & 0.7335 \\
\hline Ischemic & $29(55.8 \%)$ & $31(52.5 \%)$ & 0.7335 \\
\hline \multicolumn{4}{|c|}{ ECG } \\
\hline Sinus rhythm & $24(46.2 \%)$ & $17(28.8 \%)$ & 0.0589 \\
\hline Atrial fibrillation & $23(44.2 \%)$ & $32(59.3 \%)$ & 0.2927 \\
\hline Other & $5(9.6 \%)$ & $10(16.9 \%)$ & 0.2594 \\
\hline LBBB & $11(21.2 \%)$ & $20(33.9 \%)$ & 0.1353 \\
\hline \multicolumn{4}{|c|}{ LVEF } \\
\hline $35-45 \%, n(\%)$ & $4(7.7 \%)$ & $14(23.7 \%)$ & 0.0221 \\
\hline$\leq 35 \%, n(\%)$ & $48(92.3 \%)$ & $42(76.3 \%)$ & 0.0045 \\
\hline LVEF mean \pm SD $(\%)$ & $26.67 \pm 8.45$ & $29.57 \pm 9.92$ & 0.0992 \\
\hline \multicolumn{4}{|c|}{ Echocardiography } \\
\hline LVEDD (mm) & $64 \pm 5.27$ & $64.23 \pm 6.11$ & $\mathrm{~N}$ \\
\hline $\operatorname{LVESD}(\mathrm{mm})$ & $52.27 \pm 8.19$ & $52.27 \pm 7.7$ & $\mathrm{~N}$ \\
\hline Septum (mm) & $11.14 \pm 2.18$ & $11.05 \pm 1.94$ & $\mathrm{~N}$ \\
\hline RVDD (mm) & $41.52 \pm 7.82$ & $42.27 \pm 6.76$ & $\mathrm{~N}$ \\
\hline TRPG (mmHg) & $37.04 \pm 13.94$ & $29.95 \pm 14.31$ & 0.0096 \\
\hline TAPSE (mm) & $15.3 \pm 2.63$ & $19.8 \pm 3.58$ & $<0.0001$ \\
\hline PAPs (mmHg) & $50.44 \pm 16.47$ & $40.68 \pm 15.94$ & 0.0019 \\
\hline \multicolumn{4}{|c|}{ Blood parameters } \\
\hline Total cholesterol, mg/dL & $137.73 \pm 35.32$ & $134.24 \pm 36.53$ & 0.6110 \\
\hline Creatinine, $\mathrm{mg} / \mathrm{dL}$ & $1.29 \pm 0.85$ & $1.19 \pm 0.56$ & 0.4609 \\
\hline $\begin{array}{l}\text { Estimated GFR, } \\
\mathrm{mL} / \mathrm{min} / 1.73 \mathrm{~m}^{2}\end{array}$ & $73.05 \pm 32.61$ & $73.98 \pm 30.68$ & 0.88400 \\
\hline Sodium, $\mathrm{mmol} / \mathrm{L}$ & $137.59 \pm 3.84$ & $136.58 \pm 5.64$ & $\mathrm{~N}$ \\
\hline Potassium, $\mathrm{mmol} / \mathrm{L}$ & $4.66 \pm 0.67$ & $4.59 \pm 0.8$ & $\mathrm{~N}$ \\
\hline
\end{tabular}

There were no significant differences between the functional parameters between different genotypes; however, the $\varepsilon 2 / \varepsilon 4$ genotype showed a non-significant trend towards reduced LVEF (Figure 7A), higher LVEDD (Figure 7B), as indicators for left ventricular dysfunction, and decreased TAPSE (Figure 7C) and an increase in systolic pulmonary artery pressure (Figure 7D) as indicators for right ventricular dysfunction. 
A

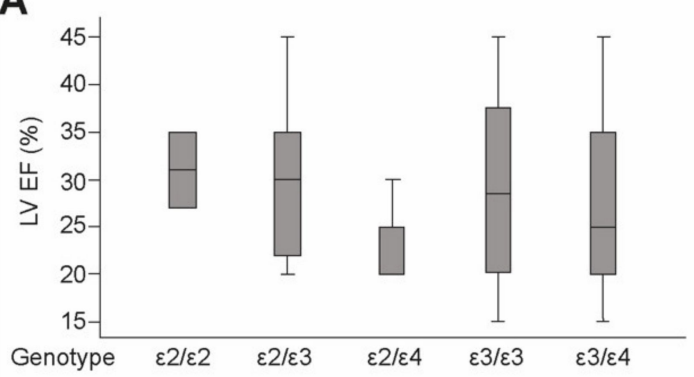

C

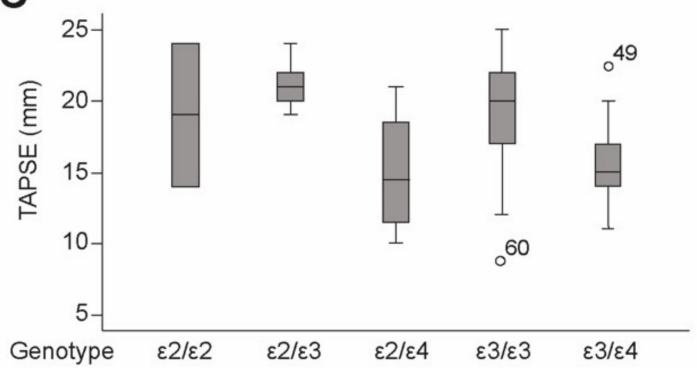

B

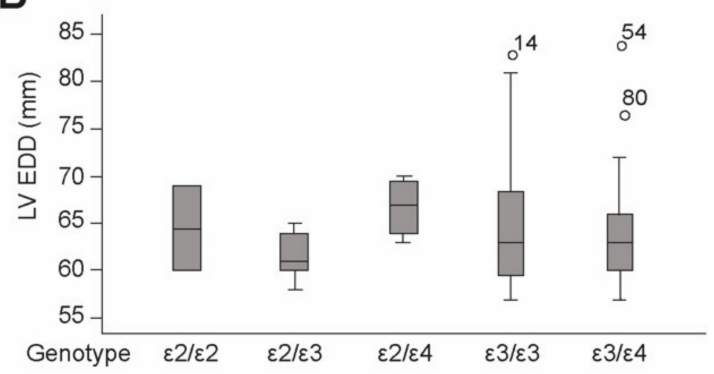

D

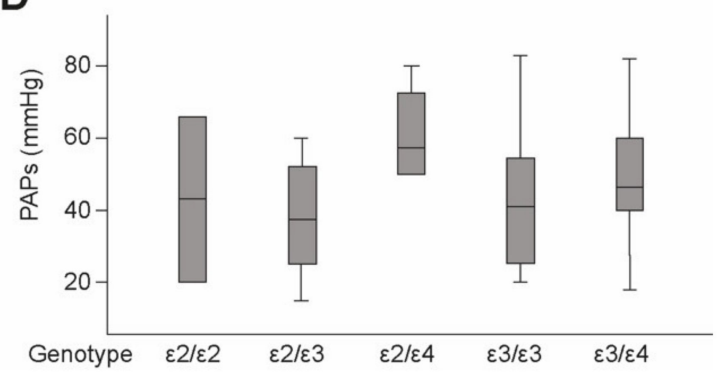

Figure 7. Functional parameters in different genotypes. (A) Left ventricular ejection fraction (LVEF), (B) left ventricular end-diastolic diameter (LVEDD), (C) tricuspid annular plane systolic excursion (TAPSE) and (D) and pulmonary arterial pressure (PAPs).

\section{Methods}

\subsection{Animal Model}

All animal experiments were performed after approval (AZ 84-02.04.2012.A277), according to the European legislation and according to the FELASA guideline for the care and use of experimental animals. Eight-week-old apoE ${ }^{+/+}$(Sprague Dawley, Charles River, Cologne, Germany) and apoE ${ }^{-/-}$(SDapoEtm1sage rats; product number: TGRA3710HM9; Compor $\mathrm{Zr}{ }^{\circledR}$ Zinc-finger nuclease target site: $5^{\prime}$ CAGGCCCTGAACCGAttctggGATTACCTGCGCTGGG; NCBI GeneID: NC_005100.2 GenBank; Sigma Aldrich Genetic Engineering Labs, Saint Louis, MO, USA) [8] rats were fed a normal diet (3.3\% crude fat, cholesterol-free) or western type diet (WD, Ssniff Spezialdiaten, Soest, Germany) for 12 weeks. Rats were kept in standardized conditions $\left(21^{\circ} \mathrm{C} \pm 2{ }^{\circ} \mathrm{C}, 60 \% \pm 5 \%\right.$ humidity, and a $12 \mathrm{~h} \mathrm{light/dark}$ cycle, free access to food and water ad libitum).

Blood analysis, including the concentration of lipids (cholesterine, triglycerides), protein and glucose, uric acid, creatinine, as well as differential blood cell count, was performed at different time points after starting the diet.

At the end-point (after 20 weeks), rats were euthanized using cervical dislocation and were subjected to necropsy examination and the organs were immediately fixed in $4 \%$ neutral buffered formalin. The collected organs (heart, lung, liver, kidney, spleen, intestine) were excised, processed, embedded in paraffin, and cut into $5 \mu \mathrm{m}$ thick sections. Sections were stained with Hematoxylin and Eosin (HE) and elastin van Gieson stain for the identification of elastic, muscles and collagen fibers and analyzed for different histological features using a light microscope.

\subsection{Organ Scores}

For the semiquantitative pattern characterization of organ structure alterations, we modified current scoring methods [9-11] to characterize specific features for each organ (Table 5): 1 -none/negligible, 2-mild, 3-moderate, 4 -moderate to severe, 5-severe. Whole sections were always evaluated using $\times 50, \times 100$ and $\times 400$ magnification ( 5 different fields per organ) and analyzed by the same blinded observer. The average of all scores was considered. 
Table 5. Histological tissue features and organ scores.

\begin{tabular}{|c|c|c|}
\hline Heart & $\begin{array}{ll}\text { - } & \text { Loose tissue composition } \\
\text { - } & \text { Vacuolization of myocardium } \\
\text { - } & \text { Thin tissue bundles } \\
\text { - } & \text { Edema } \\
\text { - } & \text { Focal inflammation (Mononuclear cells infiltration) } \\
\text { - } & \text { Focal necrosis }\end{array}$ & \\
\hline Liver & $\begin{array}{ll}\text { - } & \text { Hepatocellular vacuolization } \\
\text { - } & \text { Fongestion } \\
\text { - } & \text { Focal inflammation necrosis } \\
\end{array}$ & $\begin{array}{c}\text { Scores: } \\
\text { 1—none/negligible }\end{array}$ \\
\hline Kidney & $\begin{array}{ll}\text { - } & \text { Vacuolization of glomerular epithelium microcysts } \\
\text { - } & \text { Congestion } \\
\text { - } & \text { Increased cellularity of glomeruli } \\
\text { - } & \text { Glomerular thickening }\end{array}$ & $\begin{array}{l}\text { 2-mild } \\
\text { 3-moderate } \\
\text { 4-moderate to severe } \\
\text { 5-severe }\end{array}$ \\
\hline Lung & $\begin{array}{ll}\text { - } & \text { Edema } \\
\text { - } & \text { Congestion } \\
\text { - } & \text { Thin blood vessels } \\
\text { Thickened alveolar wall }\end{array}$ & \\
\hline Spleen & $\begin{array}{ll}\text { - } & \text { Lymphoid hyperplasia } \\
\text { - } & \text { Congestion } \\
\end{array}$ & \\
\hline Intestine & $\begin{array}{ll}- & \text { Edema } \\
- & \text { Increased cellularity of lamina propria } \\
- & \text { Fusion of villi }\end{array}$ & \\
\hline
\end{tabular}

\subsection{Morphometric Analysis}

For morphometric quantification, defined images of all hearts were obtained. Right and left ventricular wall thickness and ventricular cavity dimensions were quantified. Sirius red staining of the heart tissue was performed to quantify total collagen content in normal light and collagen type I and III in polarized light using Image J (National Institutes of Health, Bethesda, MD, USA).

Technical limitation: due to the fact that adequate equipment for measuring heart function in rats was missing, we limited our animal analysis to morphological parameters.

\subsection{Study Population}

A total of 120 Caucasian patients with heart failure (CM group) and 190 healthy outpatients (control group) were randomly selected between August 2017 and September 2019 from the Department of Cardiovascular Medicine of the University of Medicine and Pharmacy (Craiova, Romania) and included in the study. The local ethics committee approved the study protocol (No. 20/26.02.2016) and written informed consent was obtained before study enrollment from all patients.

The inclusion criteria included: (1) left ventricular ejection fraction $<45 \%$ and /or left ventricular shortening fraction $<25 \%$; left ventricular end-diastolic diameter $>3.2 \mathrm{~cm} / \mathrm{m}^{2}$ ( $>117 \%$ of normal value) and/or left ventricular end-diastolic volume $>75 \mathrm{~mL} / \mathrm{m}^{2}$, measured by transthoracic echocardiography; (2) a history of myocardial infarction or evidence of clinically significant ( $\geq 70 \%$ narrowing of a major epicardial artery) coronary artery disease (the ischemic $\mathrm{CM}=\mathrm{ICM}$ ); and (3) dilation and impaired contraction of left ventricle or both ventricles of idiopathic, familial/genetic, viral and/or immune, toxic origin, or associated with recognized cardiovascular disease in which the degree of myocardial dysfunction is not explained by normal loading conditions or the extent of ischemic damage (non-ischemic $\mathrm{CM}=\mathrm{DCM}$ ).

The exclusion criteria included: (1) acute myocardial infarction, unstable angina or percutaneous coronary intervention (PCI) within 90 days before screening, or CABG surgery within 180 days before screening; (2) previously underwent cardiac surgery with 
a remodeling procedure, left ventricular assist device placement or cardiomyoplasty; (3) cardiac resynchronization therapy (CRT) within 6 months (180 days) before screening; and (4) active myocarditis, constrictive pericarditis, restrictive, significant valvular heart disease, hypertrophic or congenital cardiomyopathy.

The healthy volunteers were recruited based on the following criteria: (1) no symptoms of cardiovascular dysfunction, (2) normal ECG, and (3) no history of chronic disease. Clinical parameters (body mass index, ECG and smoking habit) for each participant were collected.

Collected data were (1) anthropometric data (age, gender, weight, height, body surface area (BSA), body mass index (BMI)); (2) clinical data (time since diagnosis, blood pressure, heart rate, heart failure treatment, complete physical examination); (3) rest 12 leads electrocardiogram (cardiac rhythm, heart rate and potential conduction/rhythm disturbances); (4) transthoracic echocardiography (conventional measurement for left and right ventricles dimensions and function); (5) laboratory analysis (total blood count, total cholesterol, LDL cholesterol, HDL cholesterol, triglycerides, uric acid, urea, creatinine, alanine aminotransferase, aspartate aminotransferase, glycemia, erythrocyte sedimentation rate, blood sample for DNA extraction).

\subsection{Echocardiography}

Routine echocardiographic examinations were performed at the echocardiography core facility $[12,13]$. The patients were examined in the left lateral decubitus position by using the dedicated ultrasound equipment (GE-Vivid S6, Avante Health Solution, Concord, NC, USA) with a $3.5 \mathrm{MHz}$ transducer. Conventional measurements for left and right ventricles dimensions and function were obtained from standard views: the parasternal long axis view, short axis views and apical views recorded with a frame rate of a minimum of 55 frames per second. Valvular heart disease was assessed by combining Color Doppler echocardiography with spectral Doppler measurements. The LVEF was calculated in the apical four- and two-chamber views using the modified biplane Simpson's rule. Further measurements included the left ventricular end-diastolic diameter (LVEDD), the left ventricular end-systolic diameter (LVESD), the septum thickness, the right-ventricular diastolic diameter (RVDD), the tricuspid regurgitation pressure gradient (TRPG), the tricuspid annular plane systolic excursion (TAPSE) and the pulmonary arterial pressure (PAPs). All echocardiographic measurements were performed following current recommendations for chamber quantification [14] at the specialized laboratory within the Department of Cardiology, University of Medicine and Pharmacy, Craiova, Romania. Image acquisition was carried out by a single expert examiner. Stored data were analyzed offline using EchoPac version BT13 (GE Vingmed Ultrasound, Horten, Norway) dedicated software and all measurements were performed by a single experienced reader blinded about the subject's information.

\subsection{Laboratory Analysis}

Blood chemistry levels: total blood count, concentration of total cholesterol, LDL cholesterol, HDL cholesterol, triglycerides, uric acid, urea, creatinine, alanine aminotransferase, aspartate aminotransferase, glycemia and erythrocyte sedimentation rate, were performed at the hospital laboratory facility. In addition, blood samples from all participants were collected in tubes containing ethylenediaminetetraacetic acid (EDTA) and transported to the genetic human laboratory. After centrifugation, serum samples were stored at $-80{ }^{\circ} \mathrm{C}$ until analysis while the sediment was stored at $-20^{\circ} \mathrm{C}$ until DNA extraction.

\subsection{DNA Extraction}

Genomic DNA was extracted from $300 \mu \mathrm{L}$ of peripheral centrifuged blood. The isolation procedure was performed using a Wizard ${ }^{\circledR}$ Genomic DNA Purification Kit (Promega, Madison, WI, USA). Approximately $100 \mu \mathrm{L}$ of DNA was obtained at the end of the procedure. The purity and concentration of DNA were measured by a Nanodrop 2000 
(Spectrophotometer-Eppendorf Biophotometer, Wien, Austria) with DNA concentrations $($ mean $=112 \pm 9.8 \mathrm{ng} / \mu \mathrm{L})$ and optical density ratios (at 260/280 nm) $($ mean $=1.9 \pm 0.2)$. Isolated DNA samples were preserved and stored at $-20^{\circ} \mathrm{C}$ until genotyping assessments were conducted.

\subsection{Genotyping}

The analysis of apoE genotype variants was performed using the protocol from Main BF et al. [15] that we adapted. Regarding oligonucleotides, allele-specific oligonucleotide primers were designed and synthesized according to the previous literature. Each primer was specific for the single base change that resulted in either Cys or Arg at positions 112 and 158 (Table 6).

Table 6. Oligonucleotide primer sequences: primer sequence $\left(5^{\prime}-3^{\prime}\right)$. Primers D and E are similar; their differences are shown below; the same goes for primer F and G. Primer $\mathrm{H}$ is the common primer.

\begin{tabular}{cc}
\hline Primer $\mathrm{D}$ & TACTGCACCAGGCGGCCTCG \\
Primer E & TACTGCACCAGGCGGCCTCA \\
Primer F & GCCTGGTACACTGCCAGTCG \\
Primer G & GCCTGGTACACTGCCAGTCA \\
Primer $\mathrm{H}$ & AAGGAGTTGAAGGCCTACAAAT \\
\hline
\end{tabular}

PCR amplification was performed in an automated thermocycler (Thermocycler Eppendorf Mastercycler, Darmstadt, Germany) using the Promega kit GoTaq ${ }^{\circledR}$ DNA Polymerase for PCR. The total volume in each PCR reaction was $22 \mu \mathrm{L}$, including 5X GoTaq ${ }^{\circledR}$ Green, $\mathrm{MgCl} 2$ (50 mmol/L), dNTP (10 mmol/L), primers (20 pmol), template DNA, GoTaq ${ }^{\circledR}$ DNA Polymerase $(4 \mathrm{U})$ and ddH2O. Each PCR reaction contained the common primer (primer $\mathrm{H}$ ) and one of the allele-specific primers. Therefore, four reaction mixtures were required per subject for genotype diagnosis. PCR reaction condition: after an initial DNA denaturation at $96{ }^{\circ} \mathrm{C}, 40$ cycles of denaturation were performed at $96{ }^{\circ} \mathrm{C}$, annealing at $58^{\circ} \mathrm{C}$ and extending at $65^{\circ} \mathrm{C}$.

After PCR amplification, the samples were run on a horizontal electrophoresis system for $40 \mathrm{~min}$, at $150 \mathrm{w} / 150 \mathrm{~A}$ over $2 \%$ agarose gel stained with Peqgreen to highlight the bands of the DNA. A CCD camera system (G:Box Chemi HR@Syngene, Cambridge, UK) was used to visualize the banding patterns. The banding patterns were then compared to the known apoE primer combination of every genotype (Figure 8 and Table 7).

Table 7. The primer combination of every genotype. The E3/3 genotype yielding a 145 base pair product with primer $\mathrm{E}$, indicating the presence of $\mathrm{Cys} 112$, and a 277 base pair product with primer $\mathrm{F}$ indicating the presence of Arg 158. The heterozygote E3/4 produces appropriately sized products with primers $\mathrm{E}$ and $\mathrm{F}$ identifying the $\mathrm{E} 3$ allele, but also produces a 145 base pair product with primer D indicating Arg 112. Homozygous E4/4 subjects only react with primers D and F, marking the presence of Arg 112 and Arg 158, while E2/2 homozygotes only react with primers E and G, indicating Cys 112 and Cys 158.

\begin{tabular}{ccccc}
\hline Genotype & Primer D & Primer E & Primer F & Primer G \\
\hline E 2/2 & - & + & - & + \\
E 2/3 & - & + & + & + \\
E 3 3 & - & + & + & - \\
E 3 $/ 4$ & + & + & + & - \\
E 4/4 & + & - & + & - \\
E 2 /4 & + & + & + & + \\
\hline
\end{tabular}




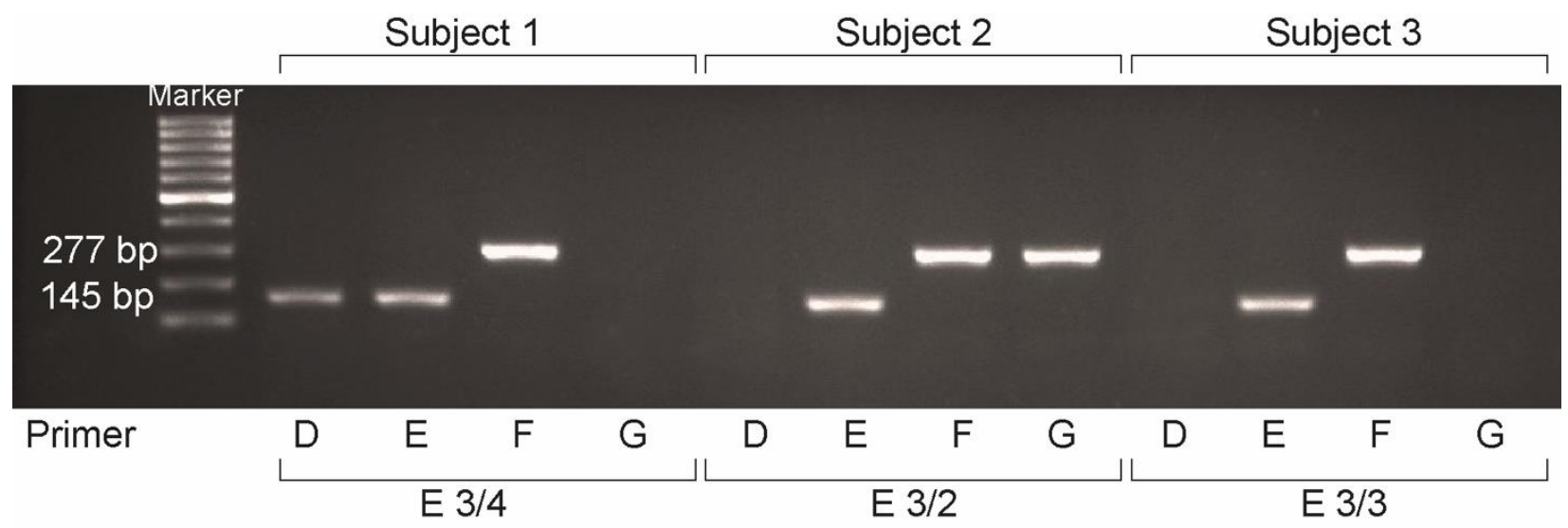

Figure 8. Apolipoprotein E genotyping using the polymerase chain reaction and allele specific oligonucleotide primers. Peqgreen-stained agarose gel showing the products from the PCR reactions. Lanes 1 through 4 are the reactions for subject 1: lane 1 is positive (primer D), lane 2 is positive (primer E), lane 3 is positive (primer F), and lane 4 is negative (primer G) indicating the $\mathrm{E} 3 / 4$ genotype. Lanes 5 through 8 are the reactions for subject 2 . Lane 5 (primer $\mathrm{D}$ ) is negative, indicating the absence of the e4 allele; lanes 6 through 8 are positive with primers E, F, and G, indicating the presence of E3 and E2 yielding a genotype of apoE 3/2. Lanes 9 through 13 are the reactions for subject 3: lane 1 is negative (primer D), lane 2 is positive (primer E), lane 3 is positive (primer F), and lane 4 is negative (primer $\mathrm{G}$ ) indicating the $\mathrm{E} 3 / 3$ genotype.

\subsection{Statistical Analysis}

Data represent the mean \pm SEM. Statistical analysis was performed with Prism 6.1 software (GraphPad). Means of two groups were compared with unpaired Student's $t$-test, more than two groups with 1-way ANOVA followed by Tukey's post hoc-test, and more than 2 variables with 2-way ANOVA and Tukey's multiple comparison test, as indicated. $p$-values of $<0.05$ were considered significant.

Baseline characteristics were assessed by standard descriptive statistics. Continuous variables are presented as the mean \pm standard deviation (SD). Categorical variables are presented as a frequency and percentage. Statistical differences between continuous variables were determined with Student's $t$-test or with one-way ANOVA, followed by Tukey's Multiple Comparisons testing, and statistical differences between categorical variables were determined with Chi Square test.

Individuals homozygous for the common genotypic variants were used as the reference to test for any association by calculating the odds ratio (OR) with a 95\% confidence interval (CI). Statistical analysis was performed with SPSS 22.0 (SPSS, Armonk, NY, USA). A $p$-value of $<0.05$ was regarded as statistically significant.

\section{Discussion}

In this study, we showed that apoE-deficient rats present multiple organ damages besides the known predisposition for obesity and affected lipid metabolism. They showed increased retention parameters, mostly after the high-fat diet, and kidney injuries, such as vacuolization, congestion and glomerular thickening. The liver showed also signs of hepatocellular vacuolization, fat deposition and focal necrosis in $\mathrm{apoE}^{-/-}$rats, the lung showed more edema and thickness of the alveolar wall, while the spleen showed more lymphoid hyperplasia in apoE ${ }^{-/-}$compared with wild-type rats.

Heart tissue showed significant morphological changes in $\mathrm{apoE}^{-/-}$rats, mostly after the high-fat diet, such as loose interstitial tissue, focal necrosis and edema. Interestingly, the right ventricle and not the left ventricle of apoE ${ }^{-/-}$rats fed the high-fat diet showed increased bundles of thin tissue and mononuclear cell infiltration. The dimensions of both ventricles were not different; however, the collagen content seemed to only be significantly affected by apoE deficiency in the right ventricle. Similarly, the collagen1/collagen3 ratio was only increased in the right ventricle of apoE ${ }^{-/-}$rats, suggesting significant changes in the extracellular matrix in the right ventricle compared with the left ventricle. 
In patients, we were able to find a correlation between the presence of the $\varepsilon 4$ allele and cardiomyopathy, but not with the etiology of the cardiomyopathy (ischemic or dilatative). While Jurkovicova et al. found $\varepsilon 2 / \varepsilon 4$ as the predominant genotype in patients with dilated cardiomyopathy [6], we found $\varepsilon 3 / \varepsilon 4$ to be the predominant genotype in our Romanian patients with ischemic or dilatative cardiomyopathy. The possible mechanisms for inducing severe forms of cardiomyopathy in the $\varepsilon 4$ allele carriers are not known and need to be investigated. Interestingly, we found also a significant association between right ventricle dysfunction and the presence of the $\varepsilon 4$ allele in the patients, which was not reported until now.

The missing or dysfunctional apoE protein, such as apoE4, is always associated with increased intracellular cholesterol and lipid accumulation and accompanied by cardiomyopathy and cardiac diastolic dysfunction [16-18]. Repetitive inflammatory and apoptotic processes are considered as the mechanisms that firstly modify the structure and then subsequently the function of the heart, being the motor of heart failure progression [19]. We can speculate that the proinflammatory [20] and proapoptotic [21] effects of apoE4 that had been reported could have a possible involvement in the progression of cardiomyopathy. For example, a possible mechanism may involve Cyclophilin A. The presence of apoE4 activates a pro-inflammatory signaling pathway in pericytes, including Cyclophilin A-nuclear factor- $\mathrm{kB}$-matrix-metalloproteinase-9 (MMP9), leading to the destruction of the blood-brain barrier, with neuronal dysfunction [22]. Additionally, in the heart, Cyclophilin $\mathrm{A}$ is the main ligand for extracellular matrix metalloproteinase inducer (EMMPRIN), being associated with the development of cardiomyopathy and heart failure in both patients and animal models [23]. However, the exact interference between Cyclophilin A and apoE in cardiovascular diseases requires further investigation.

Furthermore, apoE was found to be significantly increased in apoptotic bodies [24], which implies a role of apoE in the clearance of apoptotic bodies and dead tissue, like after myocardial infarction. Moreover, it is known that apoE is a potent inhibitor of cell proliferation and has effects on modulating angiogenesis [25] and is also involved in the repair response to tissue injury with antioxidant activity [26]. Thus, the presence of a dysfunctional apoE, such as apoE4, may impair the recovery after an injury and an inflammatory process.

The architecture of the heart is made to support a huge biomechanical burden. The fibroblasts are responsible for sustaining the cardiomyocytes' function but also for the qualitative and quantitative maintenance of the extracellular matrix. Under physiological conditions, fibroblasts are arranged in layers and strands, and are elongated and flattened cells that border on cardiomyocytes in an endomysial collagen network. This distribution model suggested from the very beginning the fundamental role of all the structures of the heart in taking over the tensile forces that appear at the parietal level [27]. Moreover, fibroblasts are actively involved in all repairing processes in the heart [28-30]. Thus, affecting fibroblasts' integrity and function represents an important factor for developing heart failure $[28,29]$. Whether apoE can affect cardiac fibroblasts and subsequently contribute to the development of dilated cardiomyopathy must be further investigated. It is known that in human fibroblasts, apoE4 binds to the SirT1, MADD, or COMMD6, known to regulate transcription by the $\mathrm{NF} \kappa \mathrm{B}$ complex, triggering the inflammatory and apoptotic pathways [31].

Recently, more studies are emphasizing a major effect of lipoproteins on cardiac function independent of coronary artery disease. For example, cholesterol-lowering therapy can reduce oxidative stress and decrease levels of tumor necrosis factor alpha, thus counteracting structural and metabolic remodeling, enhancing cardiac function [32], attenuating pressure overload-induced heart failure [33] or even preventing heart failure with preserved ejection fraction [34].

Interestingly, it seems that there is a difference between the left and right ventricle fibroblasts. In the absence of injury, right and left ventricular fibroblasts appear to have similar characteristics. However, the right ventricle has unique characteristics that make it 
susceptible to certain genetic conditions associated with interstitial remodeling, such as arrhythmogenic right ventricle cardiomyopathy. Other studies showed that the perturbation of the collagen1/collagen 3 ratio may be responsible for the increase in right ventricular stiffness [35-37]. The cellular composition of the right ventricle has not been systematically studied and the molecular links between genetic alterations and right ventricular interstitial remodeling remain unknown [35].

In the present study, we observed that the right ventricle of apoE ${ }^{-/-}$rats presented more thin tissue bundles and mononuclear cell infiltration and an increased collagen1/collagen3 ratio, while these factors remained unchanged in the left ventricle. Similarly, the $\varepsilon 4$ allele carriers showed significantly higher right ventricular dysfunction. Recently, some studies showed that apoE deficiency appears to be a novel risk factor for pulmonary artery hypertension (PAH) and patients with PAH have reduced expression of apoE in their lungs [38,39]. Additionally, apoE ${ }^{-/-}$mice develop atherosclerosis with severe PAH when fed a high-fat diet (HFD) and have increased levels of endothelin (ET)-1. Atherosclerosis and PAH have the same pathophysiological processes, such as endothelial dysfunction and increased inflammatory mediators such as IL-6 [40]. This could be a mechanism of right ventricular dysfunction independent of the left ventricle failure.

\section{Limitations}

Besides technical limitations regarding the missing equipment for performing echocardiography in rats, we can consider the absence of more advanced imaging such as Speckletracking echocardiography or cardiac MRI that would enable the better analysis of the right and left ventricular dysfunction as a limitation. However, the acquired conventional echocardiography data were enough to provide solid data and significant correlations for the current study. The small population size most likely did not affect the results because the presence of the $\varepsilon 4$ allele was significantly higher in the CM population, similar to other cohorts. Further, our study was more of an observational study based on a case-control design. However, since this is the first article reporting the relation between the presence of the $\varepsilon 4$ allele and right ventricular dysfunction, the results should be further validated in a specific risk population.

\section{Conclusions}

Our results confirm that the presence of the $\varepsilon 4$ allele is an independent risk factor for heart failure, independent of etiology and lipid metabolism. The underlying mechanisms remain to be elucidated. Moreover, we show for the first time that the presence of the $\varepsilon 4$ allele is associated with right ventricle dysfunction, implying different regulatory mechanisms of fibroblasts and extracellular matrix in both ventricles. It is essential that this is considered and thoroughly investigated before the design of therapeutical strategies for patients with heart failure.

Author Contributions: Conceptualization: R.D., M.I., F.V., E.A.L.; methodology: N.S., M.A., P.B., S.S., C.M., I.D., I.S.; formal analysis and investigation: R.D., M.A., P.B., A.C., R.A.F., S.S., T.E.-K., I.S., I.D., E.A.L.; writing—original draft preparation: R.D., E.A.L.; writing-review and editing: M.A., P.B., A.C., R.A.F., D.S., M.I., C.M., I.D., F.V.; funding acquisition: E.A.L., D.S., M.I., F.V.; resources: E.A.L., F.V.; supervision: E.A.L. All authors have read and agreed to the published version of the manuscript.

Funding: The study was supported by the Interdisciplinary Center for Clinical Research IZKF Aachen (junior research group E.A.L.). P.B. was supported by the German Research Foundation (DFG; Project-IDs 322900939, 454024652, 432698239 and 432698239). F.V. was supported by the German Research Foundation (DFG; Project-IDs GZ VO 1624/5-1). D.S. was supported by the Clinician Scientist program of the Faculty of Medicine of the RWTH Aachen University.

Institutional Review Board Statement: The animal study was conducted according to the guidelines of the Declaration of Helsinki and approved by the Institutional Review Board of Landesamt für Natur, Umwelt und Verbraucherschutz (LANUV) Nordrhein-Westfalen (approval number: AZ: 84-02.04.2012.A277, approval date: 30.11.2012) for animal experiments and the local ethics committee 
of the RWTH Aachen University (No. 20/26.02.2016.)The human study is in accordance with the Declaration of Helsinki and current guidelines. The study protocol was approved by the local ethics committee at the University of Medicine and Pharmacy Craiova (EK 099/16). Written informed consent was obtained before study enrollment from all patients.

Informed Consent Statement: Written informed consent was obtained from all subjects involved in the study.

Data Availability Statement: The data that support the findings of this study are available from the corresponding author on reasonable request.

Acknowledgments: We thank Leon Decker for the assistance with blood sample preparation and genotyping. He has provided the corresponding author with written permission to be named in the manuscript.

Conflicts of Interest: No conflict of interest.

\section{References}

1. Buzello, M.; Tornig, J.; Faulhaber, J.; Ehmke, H.; Ritz, E.; Amann, K. The apolipoprotein e knockout mouse: A model documenting accelerated atherogenesis in uremia. J. Am. Soc. Nephrol. 2003, 14, 311-316. [CrossRef] [PubMed]

2. Lo Sasso, G.; Schlage, W.K.; Boue, S.; Veljkovic, E.; Peitsch, M.C.; Hoeng, J. The Apoe(-/-) mouse model: A suitable model to study cardiovascular and respiratory diseases in the context of cigarette smoke exposure and harm reduction. J. Transl. Med. 2016, 14, 146. [CrossRef] [PubMed]

3. Getz, G.S.; Reardon, C.A. ApoE knockout and knockin mice: The history of their contribution to the understanding of atherogenesis. J. Lipid Res. 2016, 57, 758-766. [CrossRef] [PubMed]

4. Liehn, E.A.; Ponomariov, V.; Diaconu, R.; Streata, I.; Ioana, M.; Crespo-Avilan, G.E.; Hernandez-Resendiz, S.; Cabrera-Fuentes, H.A. Apolipoprotein E in Cardiovascular Diseases: Novel Aspects of an Old-fashioned Enigma. Arch. Med Res. 2018, 49, 522-529. [CrossRef] [PubMed]

5. Abondio, P.; Sazzini, M.; Garagnani, P.; Boattini, A.; Monti, D.; Franceschi, C.; Luiselli, D.; Giuliani, C. The Genetic Variability of APOE in Different Human Populations and Its Implications for Longevity. Genes 2019, 10, 222. [CrossRef] [PubMed]

6. Jurkovicova, D.; Goncalvesova, E.; Sedlakova, B.; Hudecova, S.; Fabian, J.; Krizanova, O. Is the ApoE polymorphism associated with dilated cardiomyopathy? Gen. Physiol. Biophys. 2006, 25, 3-10. [PubMed]

7. Schultheiss, H.P.; Fairweather, D.; Caforio, A.L.P.; Escher, F.; Hershberger, R.E.; Lipshultz, S.E.; Liu, P.P.; Matsumori, A.; Mazzanti, A.; McMurray, J.; et al. Dilated cardiomyopathy. Nat. Rev. Dis. Primers 2019, 5, 32. [CrossRef]

8. Cornelissen, A.; Simsekyilmaz, S.; Liehn, E.; Rusu, M.; Schaaps, N.; Afify, M.; Florescu, R.; Almalla, M.; Borinski, M.; Vogt, F. Apolipoprotein E deficient rats generated via zinc-finger nucleases exhibit pronounced in-stent restenosis. Sci. Rep. 2019, 9, 18153. [CrossRef]

9. Gibson-Corley, K.N.; Olivier, A.K.; Meyerholz, D.K. Principles for valid histopathologic scoring in research. Vet. Pathol. 2013, 50, 1007-1015. [CrossRef]

10. Cross, S.S. Grading and scoring in histopathology. Histopathology 1998, 33, 99-106. [CrossRef]

11. Srinivasan, P.K.; Sperber, V.; Afify, M.; Tanaka, H.; Fukushima, K.; Kogel, B.; Gremse, F.; Tolba, R. Novel synthetic adhesive as an effective alternative to Fibrin based adhesives. World J. Hepatol. 2017, 9, 1030-1039. [CrossRef]

12. Cherata, D.A.; Donoiu, I.; Diaconu, R.; Glodeanu, A.; Carstea, D.; Militaru, C.; Istratoaie, O. Longitudinal strain analysis allows the identification of subclinical deterioration of right ventricular function in patients with cancer therapy-related left ventricular dysfunction. Discoveries 2019, 7, e94. [CrossRef] [PubMed]

13. Neagoe, O.; Ciobanu, A.; Diaconu, R.; Mirea, O.; Donoiu, I.; Militaru, C. A rare case of familial restrictive cardiomyopathy, with mutations in MYH7 and ABCC9 genes. Discoveries 2019, 7, e99. [CrossRef]

14. Lang, R.M.; Badano, L.P.; Mor-Avi, V.; Afilalo, J.; Armstrong, A.; Ernande, L.; Flachskampf, F.A.; Foster, E.; Goldstein, S.A.; Kuznetsova, T.; et al. Recommendations for cardiac chamber quantification by echocardiography in adults: An update from the American Society of Echocardiography and the European Association of Cardiovascular Imaging. Eur. Heart J. Cardiovasc. Imaging 2015, 16, 233-270. [CrossRef] [PubMed]

15. Main, B.F.; Jones, P.J.; MacGillivray, R.T.; Banfield, D.K. Apolipoprotein E genotyping using the polymerase chain reaction and allele-specific oligonucleotide primers. J. Lipid Res. 1991, 32, 183-187. [CrossRef]

16. Zachowski, A. Phospholipids in animal eukaryotic membranes: Transverse asymmetry and movement. Biochem. J. 1993, 294 Pt 1, 1-14. [CrossRef]

17. Wood, W.G.; Igbavboa, U.; Muller, W.E.; Eckert, G.P. Cholesterol asymmetry in synaptic plasma membranes. J. Neurochem. 2011, 116, 684-689. [CrossRef]

18. Cappetta, D.; Esposito, G.; Piegari, E.; Russo, R.; Ciuffreda, L.P.; Rivellino, A.; Berrino, L.; Rossi, F.; De Angelis, A.; Urbanek, K. SIRT1 activation attenuates diastolic dysfunction by reducing cardiac fibrosis in a model of anthracycline cardiomyopathy. Int. J. Cardiol. 2016, 205, 99-110. [CrossRef] 
19. Diaconu, R.; Donoiu, I.; Mirea, O.; Balseanu, T.A. Testosterone, cardiomyopathies, and heart failure: A narrative review. Asian J. Androl. 2021, 23, 348-356. [CrossRef]

20. DeKroon, R.M.; Mihovilovic, M.; Goodger, Z.V.; Robinette, J.B.; Sullivan, P.M.; Saunders, A.M.; Strittmatter, W.J. ApoE genotypespecific inhibition of apoptosis. J. Lipid Res. 2003, 44, 1566-1573. [CrossRef] [PubMed]

21. Lynch, J.R.; Tang, W.; Wang, H.; Vitek, M.P.; Bennett, E.R.; Sullivan, P.M.; Warner, D.S.; Laskowitz, D.T. APOE genotype and an ApoE-mimetic peptide modify the systemic and central nervous system inflammatory response. J. Biol. Chem. 2003, 278, 48529-48533. [CrossRef]

22. Bell, R.D.; Winkler, E.A.; Singh, I.; Sagare, A.P.; Deane, R.; Wu, Z.; Holtzman, D.M.; Betsholtz, C.; Armulik, A.; Sallstrom, J.; et al. Apolipoprotein E controls cerebrovascular integrity via cyclophilin A. Nature 2012, 485, 512-516. [CrossRef]

23. Siwik, D.A.; Kuster, G.M.; Brahmbhatt, J.V.; Zaidi, Z.; Malik, J.; Ooi, H.; Ghorayeb, G. EMMPRIN mediates beta-adrenergic receptor-stimulated matrix metalloproteinase activity in cardiac myocytes. J. Mol. Cell. Cardiol. 2008, 44, 210-217. [CrossRef] [PubMed]

24. Heeren, J.; Grewal, T.; Laatsch, A.; Becker, N.; Rinninger, F.; Rye, K.A.; Beisiegel, U. Impaired recycling of apolipoprotein E4 is associated with intracellular cholesterol accumulation. J. Biol. Chem. 2004, 279, 55483-55492. [CrossRef]

25. Vogel, T.; Guo, N.H.; Guy, R.; Drezlich, N.; Krutzsch, H.C.; Blake, D.A.; Panet, A.; Roberts, D.D. Apolipoprotein E: A potent inhibitor of endothelial and tumor cell proliferation. J. Cell. Biochem. 1994, 54, 299-308. [CrossRef] [PubMed]

26. Zito, G.; Polimanti, R.; Panetta, V.; Ventriglia, M.; Salustri, C.; Siotto, M.C.; Moffa, F.; Altamura, C.; Vernieri, F.; Lupoi, D.; et al. Antioxidant status and APOE genotype as susceptibility factors for neurodegeneration in Alzheimer's disease and vascular dementia. Rejuvenation Res. 2013, 16, 51-56. [CrossRef]

27. Porter, K.E.; Turner, N.A. Cardiac fibroblasts: At the heart of myocardial remodeling. Pharmacol. Ther. 2009, 123, 255-278. [CrossRef]

28. Panin, L.E.; Russkikh, G.S.; Polyakov, L.M. Detection of apolipoprotein A-I, B, and E immunoreactivity in the nuclei of various rat tissue cells. Biochemistry 2000, 65, 1419-1423. [CrossRef]

29. Theendakara, V.; Peters-Libeu, C.A.; Spilman, P.; Poksay, K.S.; Bredesen, D.E.; Rao, R.V. Direct Transcriptional Effects of Apolipoprotein E. J. Neurosci. 2016, 36, 685-700. [CrossRef] [PubMed]

30. Liehn, E.A.; Postea, O.; Curaj, A.; Marx, N. Repair after myocardial infarction, between fantasy and reality: The role of chemokines. J. Am. Coll. Cardiol. 2011, 58, 2357-2362. [CrossRef]

31. Ltic, S.; Perovic, M.; Mladenovic, A.; Raicevic, N.; Ruzdijic, S.; Rakic, L.; Kanazir, S. Alpha-synuclein is expressed in different tissues during human fetal development. J. Mol. Neurosci. 2004, 22, 199-204. [CrossRef] [PubMed]

32. Muthuramu, I.; Amin, R.; Postnov, A.; Mishra, M.; Aboumsallem, J.P.; Dresselaers, T.; Himmelreich, U.; Van Veldhoven, P.P.; Gheysens, O.; Jacobs, F.; et al. Cholesterol-Lowering Gene Therapy Counteracts the Development of Non-ischemic Cardiomyopathy in Mice. Mol. Ther. 2017, 25, 2513-2525. [CrossRef] [PubMed]

33. Muthuramu, I.; Mishra, M.; Aboumsallem, J.P.; Postnov, A.; Gheysens, O.; De Geest, B. Cholesterol lowering attenuates pressure overload-induced heart failure in mice with mild hypercholesterolemia. Aging 2019, 11, 6872-6891. [CrossRef]

34. Aboumsallem, J.P.; Muthuramu, I.; Mishra, M.; De Geest, B. Cholesterol-Lowering Gene Therapy Prevents Heart Failure with Preserved Ejection Fraction in Obese Type 2 Diabetic Mice. Int. J. Mol. Sci. 2019, 20, 2222. [CrossRef]

35. Frangogiannis, N.G. Fibroblasts and the extracellular matrix in right ventricular disease. Cardiovasc. Res. 2017, 113, 1453-1464 [CrossRef] [PubMed]

36. Wei, S.; Chow, L.T.; Shum, I.O.; Qin, L.; Sanderson, J.E. Left and right ventricular collagen type I/III ratios and remodeling post-myocardial infarction. J. Card. Fail. 1999, 5, 117-126. [CrossRef]

37. Rigolin, V.H.; Robiolio, P.A.; Wilson, J.S.; Harrison, J.K.; Bashore, T.M. The forgotten chamber: The importance of the right ventricle. Cathet. Cardiovasc. Diagn. 1995, 35, 18-28. [CrossRef] [PubMed]

38. Umar, S.; Partow-Navid, R.; Ruffenach, G.; Iorga, A.; Moazeni, S.; Eghbali, M. Severe pulmonary hypertension in aging female apolipoprotein E-deficient mice is rescued by estrogen replacement therapy. Biol. Sex Differ. 2017, 8, 9. [CrossRef] [PubMed]

39. Yao, X.; Gordon, E.M.; Figueroa, D.M.; Barochia, A.V.; Levine, S.J. Emerging Roles of Apolipoprotein E and Apolipoprotein A-I in the Pathogenesis and Treatment of Lung Disease. Am. J. Respir. Cell Mol. Biol. 2016, 55, 159-169. [CrossRef] [PubMed]

40. Renshall, L.; Arnold, N.; West, L.; Braithwaite, A.; Pickworth, J.; Walker, R.; Alfaidi, M.; Chamberlain, J.; Casbolt, H.; Thompson, A.A.R.; et al. Selective improvement of pulmonary arterial hypertension with a dual ETA/ETB receptors antagonist in the apolipoprotein E(-/-) model of PAH and atherosclerosis. Pulm. Circ. 2018, 8, 2045893217752328. [CrossRef] 